\title{
Heparin-binding EGF-like growth factor and miR-1192 exert opposite effect on Runx2-induced osteogenic differentiation
}

\author{
S Yu ${ }^{1,4}, Q$ Geng ${ }^{1,4}, \mathrm{~J} \mathrm{Ma}^{2}, \mathrm{~F} \mathrm{Sun}^{3}, \mathrm{Y} Y \mathrm{u}^{2}, \mathrm{Q} \mathrm{Pan}^{\star, 2}$ and A Hong ${ }^{*, 1}$
}

Osteoblast differentiation is a pivotal event in bone formation. Runt-related transcription factor-2 (Runx2) is an essential factor required for osteoblast differentiation and bone formation. However, the underlying mechanism of Runx2-regulated osteogenic differentiation is still unclear. Here, we explored the corresponding mechanism using the $\mathrm{C} 2 \mathrm{C} 12 / \mathrm{Run}^{\mathrm{D}} 2^{\mathrm{Dox}}$ subline, which expresses Runx2 in response to doxycycline (Dox). We found that Runx2-induced osteogenic differentiation of C2C12 cells results in a sustained decrease in the expression of heparin-binding EGF-like growth factor (HB-EGF), a member of the epidermal growth factor (EGF) family. Forced expression of HB-EGF or treatment with HB-EGF is capable of reducing the expression of alkaline phosphatase (ALP), a defined marker of early osteoblast differentiation. HB-EGF-mediated inhibition of ALP depends upon activation of the EGFR and the downstream extracellular signal-regulated kinase, c-Jun $\mathrm{N}$-terminal kinase mitogen-activated protein kinase pathways as well as phosphatidylinositol 3-kinase/Akt pathway. Runx2 specifically binds to the Hbegf promoter, suggesting that Hbegf transcription is directly inhibited by Runx2. Runx2 can upregulate miR-1192, which enhances Runx2-induced osteogenic differentiation. Moreover, miR-1192 directly targets Hbegf through translational inhibition, suggesting enhancement of Runx2-induced osteogenic differentiation by miR-1192 through the downregulation of HB-EGF. Taken together, our results suggest that Runx2 induces osteogenic differentiation of $\mathrm{C} 2 \mathrm{C} 12$ cells by inactivating HB-EGF-EGFR signaling through the downregulation of HB-EGF via both transcriptional and post-transcriptional mechanisms.

Cell Death and Disease (2013) 4, e868; doi:10.1038/cddis.2013.363; published online 17 October 2013

Subject Category: Experimental Medicine

Runt-related transcription factor-2 (Runx2, also known as Cbfa1, Osf2, and AML3), a member of the runt-domain gene family, ${ }^{1}$ has been reported to have a key role in osteoblast differentiation and bone formation. In mice with deletion of the Runx2 gene (Runx $2^{-1-}$ ), formation of mineralized bone was completely abolished, and the mice die soon after birth, ${ }^{2}$ whereas mice overexpressing Runx2 under the control of the $\alpha 1$ (I) collagen promoter show osteopenia with multiple fractures. $^{3}$ Several in vitro studies have also shown that calvaria-derived cells of Cbfa1-deficient mice do not generate bone nodules in the presence of bone morphogenetic protein2 (BMP-2), ${ }^{4}$ and that forced expression of Runx2 can induce transdifferentiation of mouse primary skeletal myoblasts into osteoblasts. ${ }^{5}$ In addition, the regulation of Runx2 activity via post-translational modification is also important for osteogenesis. For instance, C-Jun N-terminal kinase 1(JNK1) was reported to functionally inhibit BMP-2-induced osteogenic differentiation of $\mathrm{C} 2 \mathrm{C} 12$ cell through phosphorylation of Runx2 at Ser104. ${ }^{6}$ P300 and p300/CBP-associated factor (PCAF) were found to promote osteogenic differentiation of C2C12 and MC3T3 cells through acetylation of Runx2. ${ }^{7-9}$ Moreover, the E3 ubiquitin ligases Smad ubiquitin regulatory factor 1 (Smurf1) and $\mathrm{C}$ terminus of Hsc70-interacting protein (CHIP) were verified to regulate negatively osteoblast differentiation by promoting Runx2 ubiquitin-dependent proteosomal degradation. ${ }^{10,11}$

MicroRNAs (miRNAs), a set of small (22 nucleotides), highly conserved, endogenous noncoding RNA, are involved in diverse biological and pathological processes. They function at the post-transcriptional level by mediating translational repression or mRNA degradation of their target gene through imperfect binding to the $3^{\prime}$-untranslated region

\footnotetext{
${ }^{1}$ Institute of Biomedicine, College of Life Science and Technology, Jinan University, Guangdong, Guangzhou, People's Republic of China; ${ }^{2}$ Central Laboratory, People's 10th Hospital, Shanghai, People's Republic of China and ${ }^{3}$ Department of Medical Laboratory, People's 10th Hospital, Shanghai, People's Republic of China *Corresponding authors: Q Pan, Central Laboratory, Shanghai 10th People's Hospital, No. 301 Middle Yanchang Road, Shanghai, Zhabei District 200072, People's Republic of China. Tel: +86 021 66303403; Fax: +86 021 66303403; E-mail: panqiuhui@263.net

or A Hong, Institute of Biomedicine, College of Life Science and Technology, Jinan University, No. 601 Huangpu Avenue West, Guangdong, Tianhe District, Guangzhou 510632, People's Republic of China. Tel: +86 020 85221983; Fax: +86 020 85221983; E-mail: tha@ @nu.edu.cn

${ }^{4}$ These authors contributed equally to this work.

Keywords: miR-1192; HB-EGF; Runx2; osteogenic differentiation

Abbreviations: Runx2, runt-related transcription factor-2; BMP-2, bone morphogenetic protein-2; PCAF, p300/CBP-associated factor; Smurf1, Smad ubiquitin regulatory factor; CHIP, C terminus of Hsc70-interacting protein; MSCs, mesenchymal stem cells; HB-EGF, heparin-binding EGF-like growth factor; EGF, epidermal growth factor; EGFR, EGF receptor; MAPK, mitogen-activated protein kinase; ERK, extracellular signal-regulated kinase; JNK, c-Jun N-terminal kinase; PI3K, phosphatidylinositol 3-kinase; Dox, doxycycline; qPCR, quantitative PCR; ALP, alkaline phosphatase; OC, osteocalcin; Ibsp, integrin-binding secreted protein; Spp1, secreted phosphoprotein 1; Myog, myogenin; Des, desmin; Cdh15, cadherin 15; Sp7, Sp7 transcription factor; Twist2, twist-related protein 2; Shn3, schnurri-3; Maf, transcription factor maf; $3^{\prime}$-UTR, $3^{\prime}$-untranslated region; EMSA, electrophoretic mobility shift assay; ChIP, chromatin immunoprecipitation

Received 11.6.13; revised 06.8.13; accepted 09.8.13; Edited by Y Shi
} 
(3'-UTR) of target mRNA. Several studies have demonstrated the crucial role of Runx2-miRNA network in osteogenesis. MiR-133 directly targets Runx2 and inhibits BMP-2-induced osteogenic differentiation of $\mathrm{C} 2 \mathrm{C} 12$ cells. ${ }^{12}$ In bone marrowderived mesenchymal stem cells (MSCs), miR-204/211 stimulates adipocyte differentiation and inhibits osteogenic differentiation through the regulation of Runx2. ${ }^{13}$ Recently, a panel of 11 miRNAs, including miR-133 and -204/211, was found to control osteogenic lineage progression by targeting Runx2. ${ }^{14}$ Moreover, a network connecting Runx2, SATB2, and the miR-23a-27a-24-2 cluster was verified to regulate the osteoblast differentiation program. ${ }^{15}$ In addition, an autoregulatory feedback loop, which was identified between Runx2 and the miR-3960/miR-2861 cluster, has important role in BMP-2-induced osteogenesis of ST2 stromal cells. ${ }^{16}$ However, the role of Runx2-miRNA network in osteogenesis needs further investigation.

Heparin-binding EGF-like growth factor (HB-EGF), a member of the epidermal growth factor (EGF) family, is synthesized as a membrane-anchor form (pro-HB-EGF). Pro-HB-EGF is cleaved at the cell surface to yield the soluble form of HB-EGF (sHB-EGF). ${ }^{17}$ Subsequently, sHB-EGF directly binds to both EGF receptor (EGFR) and ErbB4, ${ }^{18}$ which triggers receptor dimerization and activates downstream kinases, including extracellular signal-regulated kinase (ERK), JNK, and phosphatidylinositol 3-kinase (PI3K). ${ }^{19}$ It has been reported that osteoblast differentiation and bone formation can be regulated by EGFR signaling. For instance, HB-EGF-EGFR signaling negatively regulates osteogenic differentiation of both MC3T3-E1 cells and human bone marrow-derived MSCs in vitro. ${ }^{20,21}$ In EGFR-deficient mice, osteoblast proliferation and differentiation are abnormal, and finally bone formation and skeleton structure are impaired. ${ }^{22}$ However, the relationship between Runx2 and EGFR signaling has not been well discussed during osteogenesis.

Here, we showed that HB-EGF inhibits Runx2-induced early osteoblast differentiation of $\mathrm{C} 2 \mathrm{C} 12$ cells through activation of EGFR and downstream pathways. We demonstrated that upregulated miR-1192 by Runx2 potentiates Runx2-induced osteogenic differentiation. Furthermore, we discovered that Hbegf transcription is inhibited by Runx2 through direct binding to its promoter, and miR-1192 directly targets Hbegf through translational inhibition. Taken together, our findings point to a novel mechanism of Runx2-induced osteogenic differentiation, which involves the inactivation of HB-EGF-EGFR signaling through the downregulation of HB-EGF at both the transcriptional and post-transcriptional levels.

\section{Results}

Runx2 inhibits myogenic differentiation and induces osteoblast differentiation in $\mathbf{C 2 C 1 2}$ cells. Runx2 overexpression is known to induce osteoblast phenotypic markers in a number of cell types. ${ }^{5,23,24}$ Here, we demonstrated that osteogenic differentiation is induced by Runx2 in $\mathrm{C} 2 \mathrm{C} 12$, MC3T3, and C3H10T1/2 cells (Supplementary Figure S1), especially in $\mathrm{C} 2 \mathrm{C} 12$ cells. Thus, we established C2C12/ Runx $2^{\text {Dox }}$ subline, which expresses a Flag-Runx2 protein upon treatment with doxycycline (Dox), and used it to explore the underlying mechanism of Runx2-regulated osteogenesis. In Dox-treated cells, the expression of mRNA (Figure 1a) and protein (Figure 1b) for Flag-Runx2 was increased in a time-dependent manner. In immunocytochemistry analysis, Flag-Runx2 was mainly expressed in the nuclei after Dox treatment, and upregulation of Flag-Runx2 occurred in about $50 \%$ of Dox-treated cells (Figure 1c). The osteoblast phenotype was confirmed by demonstration of increased alkaline phosphatase (ALP) activity and Alizarin Red staining for matrix mineralization (Figure 1d). Upregulation of osteoblastic markers by Runx2, such as Alp, osteocalcin (OC), integrin-binding secreted protein (Ibsp), and secreted phosphoprotein 1(Spp1), was confirmed by real-time quantitative PCR (qPCR) analysis (Figure 1e and Supplementary Figure S2). In addition, expression of myogenin (Myog), desmin (Des), and cadherin 15 (Cdh15), which are related to the myogenic differentiation, was downregulated in Doxtreated cells (Figure 1f), indicating that Runx2 inhibits myogenic differentiation of $\mathrm{C} 2 \mathrm{C} 12$ cells. Taken together, these results suggest that Runx2 inhibits myogenic differentiation and induces osteogenic differentiation in $\mathrm{C} 2 \mathrm{C} 12$ cells.

HB-EGF inhibits Runx2-induced early osteoblast differentiation of $\mathbf{C 2 C 1 2}$ cells. EGFR signaling can regulate osteoblast differentiation and bone development. ${ }^{20-22}$ Expression of Hbegf increases steadily during myogenic differentiation of $\mathrm{C} 2 \mathrm{C} 12$ cells. $^{25}$ These results led us to speculate that EGFR signaling may be involved in Runx2induced osteogenic differentiation of $\mathrm{C} 2 \mathrm{C} 12$ cells. Therefore, we examined the expression of EGF family members and their receptors, and found that the expression of Hbegf and Epiregulin (Ereg), the ligands for EGFR, was gradually downregulated in Dox-treated cells (Figure 2a and Supplementary Figure S3). No significant changes were observed for others. These findings suggest the possibility that EGFR signaling negatively regulates Runx2-induced osteogenic differentiation of $\mathrm{C} 2 \mathrm{C} 12$ cells. To test this hypothesis, Hbegf and Ereg expression vectors were used for transfection of C2C12/Runx $2^{\text {Dox }}$ cells. Real-time qPCR data revealed that $H b e g f$ overexpression decreases Alp expression, a defined marker of early osteoblast differentiation. However, expression of $O C$, a marker of late osteoblast differentiation, was not affected (Figure 2b). Interestingly, Ereg overexpression had no effect on the expression of Alp and OC (data not shown). We also examined the expression of $A / p$ and $O C$ after treating C2C12/Runx $2^{\text {Dox }}$ cells with different HB-EGF concentrations, and found that Alp expression was inhibited by HB-EGF treatment, whereas $O C$ expression was not affected (Figure 2c). Moreover, ALP activity was decreased in HB-EGF-treated cells (Figure 2d). These results suggest that HB-EGF-mediated signaling inhibits Runx2-induced early osteoblast differentiation of $\mathrm{C} 2 \mathrm{C} 12$ cells but has no effect on late osteoblast differentiation.

HB-EGF inhibits Runx2-induced early osteoblast differentiation using multiple signaling pathways. HB-EGF activates ERK, JNK, and PI3K/Akt pathways through activation of EGFR, ${ }^{19}$ raising the possibility that HB-EGF 


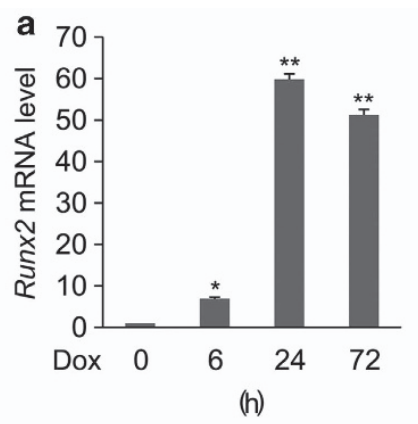

b

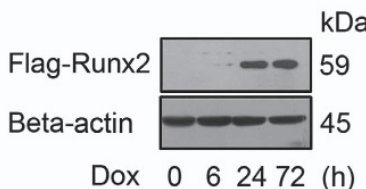

C DAPI
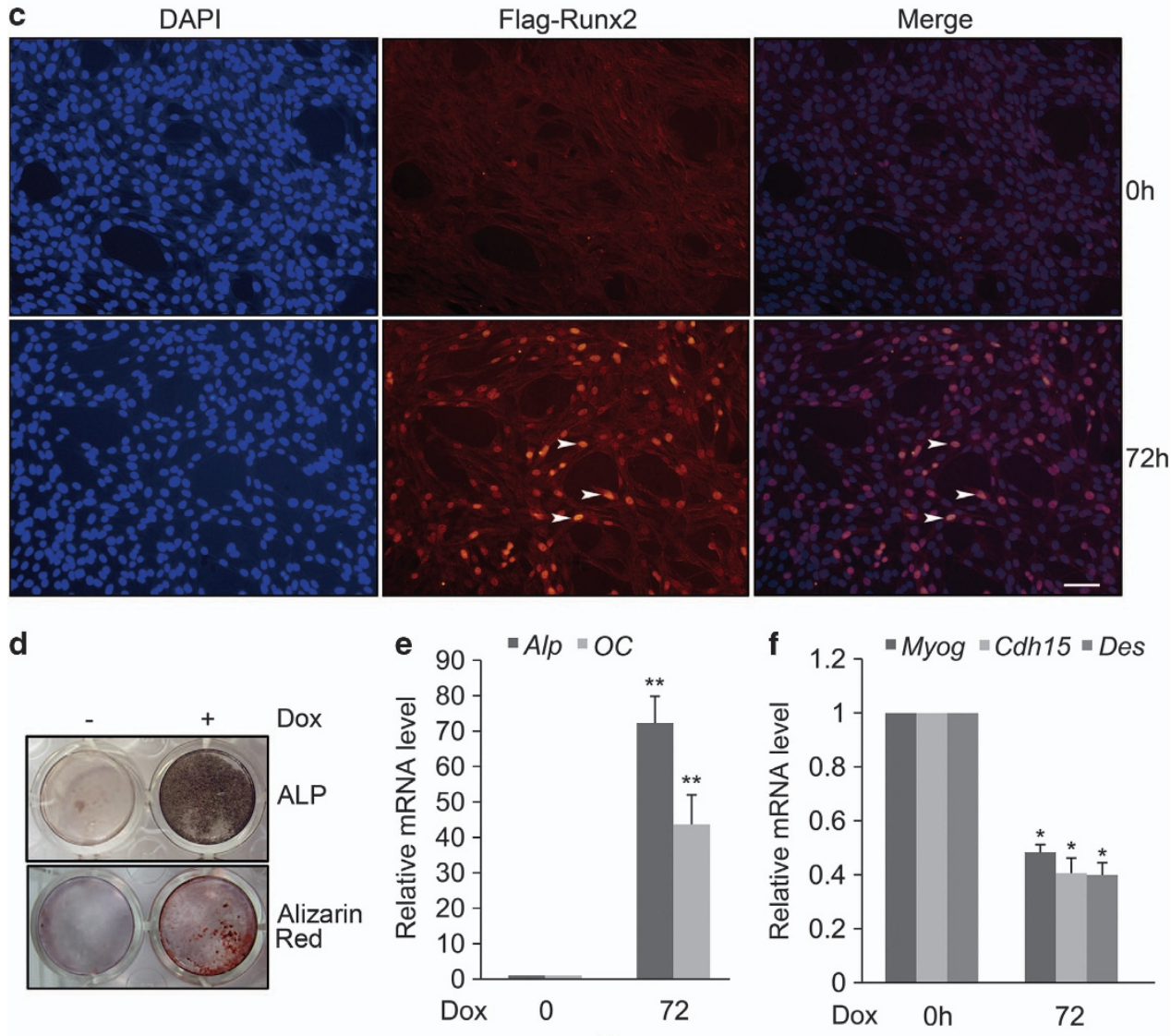

(h)

(h)

Figure 1 Runx2 inhibits myogenic differentiation and induces osteoblast differentiation in $\mathrm{C} 2 \mathrm{C} 12$ cells. (a and $\mathbf{b})$ Established C2C12/Runx $2^{\text {Dox }}$ subline with conditional Runx2 expression. C2C12/Runx2 ${ }^{\text {Dox }}$ cells were treated with Dox for the times indicated and subjected to real-time qPCR analysis for Runx2 mRNA (a) and western blot analysis with anti-Flag antibody to detect Flag-Runx2 (b). Data are presented as mean \pm S.D. $(n=3) .{ }^{\star} P<0.05,{ }^{\star \star} P<0.01$ compared with untreated cells $(0 \mathrm{~h})$. (c) Detection of Flag-Runx2 by immunofluorescence microscopy. Immunofluorescence staining for Flag-Runx2 (red) revealed the nuclear distribution (arrow) of Runx2. DAPI was used to visualize nuclei. Scale bar in micrograph represents $20 \mu \mathrm{m}$. (d) ALP- and matrix-mineralizing activity were measured by ALP and Alizarin Red staining in Dox-treated cells at days 7 and 21, respectively. Similar results were obtained in three independent experiments. (e and f) Real-time qPCR results of $A / p(\mathbf{e}), O C(\mathbf{e}), M y o g(\mathbf{f}), C d h 15(\mathbf{f})$, and $D e s$ (f) in Dox-treated cells. Data are presented as mean \pm S.D. $(n=3) .{ }^{*} P<0.05,{ }^{* *} P<0.01$ compared with untreated cells $(0 \mathrm{~h})$

inhibits Runx2-induced early osteoblast differentiation using EGFR-dependent signaling. To test this hypothesis, we detected the phosphorylation of EGFR, ERK, JNK, and Akt in HB-EGF-treated cells. As shown in Figure 3a, C2C12/ Runx $2^{\text {Dox }}$ cells induced a rapid increase in the phosphorylation of EGFR, ERK, JNK, and Akt within 1 min after treatment. The phosphorylation of EGFR and Akt reached the maximum at 5 and $2 \mathrm{~min}$, and rapidly declined to nearly the basal level at 10 and $5 \mathrm{~min}$, respectively.
The phosphorylation of ERK and JNK reached the peak at 2 and $5 \mathrm{~min}$, respectively, and gradually decreased. These results indicate that the EGFR, ERK, and JNK mitogenactivated protein kinase (MAPK) pathways as well as PI3K/ Akt pathway can be activated rapidly in response to HB-EGF in C2C12/Runx2 $2^{\text {Dox }}$ cells.

To determine whether the HB-EGF-induced phosphorylation of ERK, JNK, and Akt was EGFR dependent, we used an inhibitor of EGFR kinase (i.e., AG1478), and examined its effect 

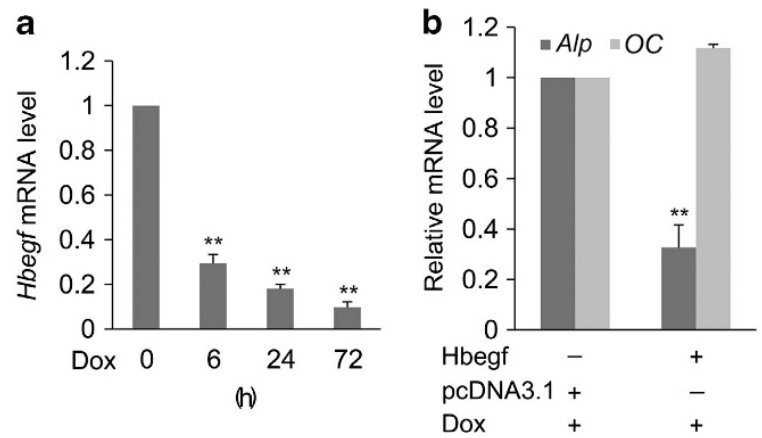

C

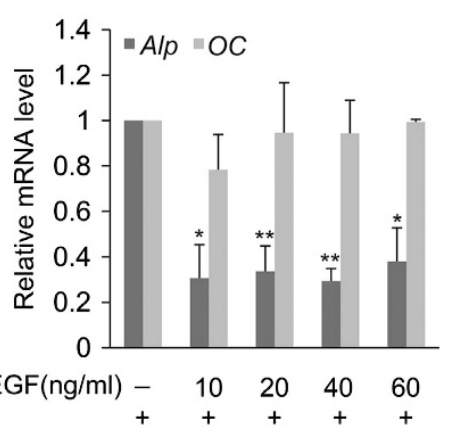

$\begin{array}{llllll}\text { HB-EGF }(\mathrm{ng} / \mathrm{ml}) & - & 10 & 20 & 40 & 60 \\ \operatorname{Dox} & + & + & + & + & +\end{array}$

d

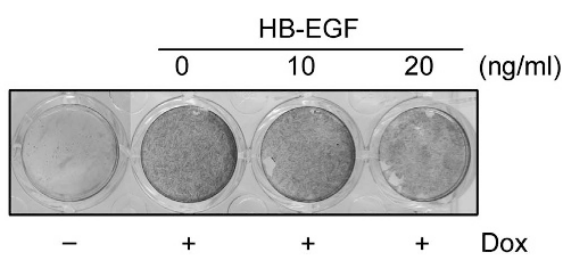

Figure 2 HB-EGF inhibits Runx2-induced early osteoblast differentiation of C2C12 cells. (a) Real-time qPCR result of $H b e g f$ in Dox-treated cells. Data are presented as mean \pm S.D. $(n=3) .{ }^{*} P<0.01$ compared with untreated cells $(0 \mathrm{~h})$. (b) The empty vector (pcDNA3.1) or HB-EGF expression vector (pcDNA3.1-Hbegf) was transfected into C2C12/Runx $2^{\text {Dox }}$ cells. The transfected cells were treated with Dox for 3 days and subjected to real-time qPCR analysis for Alp and OC mRNA. Data are presented as mean \pm S.D. $(n=3) .{ }^{* *} P<0.01$ compared with pcDNA3.1-transfected cells. (c) C2C12/Runx2 ${ }^{\text {Dox }}$ cells were treated with the indicated concentration of HB-EGF in the presence of Dox for $72 \mathrm{~h}$, and the mRNA level of $A / p$ and $O C$ was determined by real-time qPCR analysis. Data are presented as mean \pm S.D. ( $n=3$ ). $P<0.05$, ${ }^{* *} P<0.01$ compared with Dox-treated cells. (d) Effect of HB-EGF on ALP activity. C2C12/Runx $2^{\text {Dox }}$ cells were treated with the indicated concentration of HB-EGF in the presence of Dox for 7 days, and the ALP activity was measured by ALP staining. Similar results were obtained in three independent experiments

on HB-EGF-induced phosphorylation of the aforementioned kinases. The maximum phosphorylations of these kinases were all inhibited by AG1478 (Figure 3b), suggesting that the effect of HB-EGF on phosphorylation of ERK, JNK, and Akt is mediated through activation of EGFR. Furthermore, if C2C12/ Runx $2^{\text {Dox }}$ cells were treated with the specific inhibitor for ERK (i.e., PD98059), JNK (i.e., SP600125), or PI3K/Akt (i.e., LY294002), HB-EGF-induced phosphorylation of the specific target kinase was inhibited but not the other kinases (Figure $3 b$ ), indicating that the phosphorylation of ERK, JNK, and Akt is induced by HB-EGF in a parallel manner.

To test whether HB-EGF-mediated EGFR activation contributed to inhibition of $A / p$ expression, we treated C2C12/ Runx $2^{\text {Dox }}$ cells with AG1478, and found that Alp expression was upregulated after treatment (Figure $3 c$ ). This result indicates that inhibition of $A / p$ expression by HB-EGF is mediated mainly through activation of EGFR. To further investigate whether inhibition of Alp expression by HB-EGF is mediated through the MAPK- or PI3K/Akt-dependent pathway, we treated C2C12/ Runx $2^{\text {Dox }}$ cells with an inhibitor of any of the aforementioned pathways, and found that Alp expression was also upregulated after treatment (Figure 3c). Therefore, we concluded that all three pathways are utilized by HB-EGF to inhibit Runx2-induced early osteoblast differentiation of C2C12 cells.

Inhibition of Runx2-induced early osteoblast differentiation by HB-EGF partially mediated through repression of Runx2 function. Elucidating HB-EGF-regulated genes could provide insight into the mechanism of inhibition of Runx2-induced early osteoblast differentiation by HB-EGF. Thus, C2C12/Runx2 ${ }^{\text {Dox }}$ cells were transfected with the Hbegf expression vector or empty vector, and then subjected to mRNA profiling analysis after 1 and 3 days of treatment with Dox (Supplementary Figure S4). Using a fold-change cutoff of 1.4 , we selected 140 genes whose expression changed at both time points, and identified 32 genes involved in this differentiation process. Among these genes, 12 genes were upregulated and 20 genes were downregulated (Figure 4a). Three identified genes, twist-related protein 2 (Twist2), schnurri-3 (Shn3, also known as Hivep3), and transcription factor maf (Maf), are closely related to Runx2 function (red boxes in Figure $4 a$ )..$^{26-28}$ The effect of HB-EGF on expression of these three genes was confirmed in HBEGF-treated cells (Figure 4b). Moreover, the effect of HB-EGF on these genes was abrogated by AG1478 (Figure 4c), indicating the regulation of these genes by HB-EGF through activation of EGFR. HB-EGF-induced Shn3 upregulation was abolished by PD98059, SP600125, or LY294002, suggesting that ERK, JNK, and PI3K/Akt pathways are involved in the regulation of Shn3 expression by HB-EGF (Figure 4c). HB-EGF-induced Twist2 upregulation and Maf downregulation were diminished in the presence of PD98059 or LY294002, but not SP600125, indicating that expression of Twist2 and Maf is regulated by HB-EGF through activation of ERK and PI3K/Akt pathways, not JNK pathway (Figure 4c). Given the regulation of the expression of Shn3, Twist2, and Maf by HB-EGF, and the roles of these factors in the regulation of 


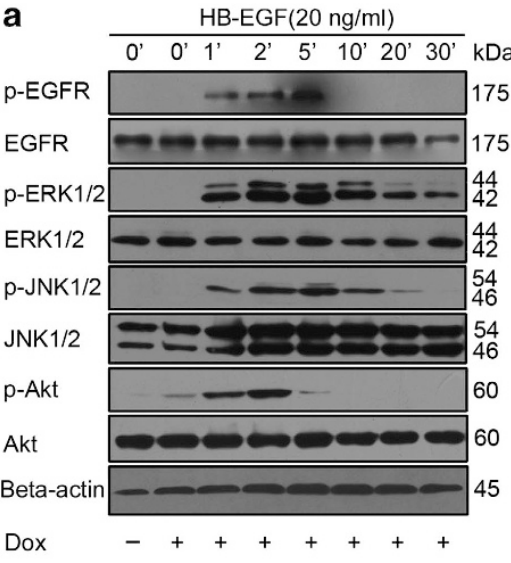

b
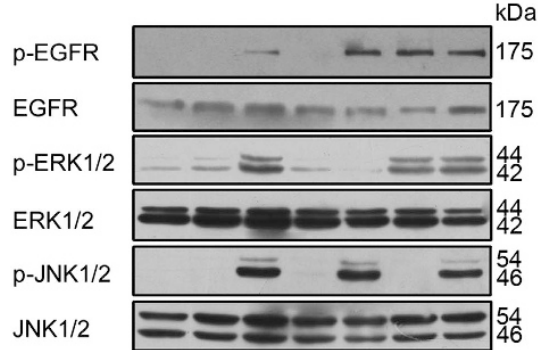

p-Akt

Akt

Beta-actin

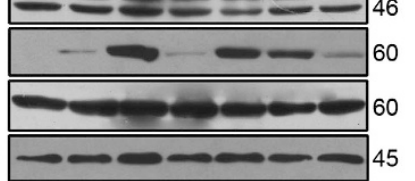

HB-EGF(20 ng/ml) - -++++ $\mathrm{AG} 1478(1 \mu \mathrm{M})$ - $\quad$ - + - -

$\mathrm{PD} 98059(20 \mu \mathrm{M})$ - $\quad$ - $\quad+\quad-$

$\mathrm{SP} 600125(10 \mu \mathrm{M})-\quad-\quad-\quad+$

LY294002 $(10 \mu \mathrm{M})$ - $-\quad-\quad-+$

Dox

$-+++++$

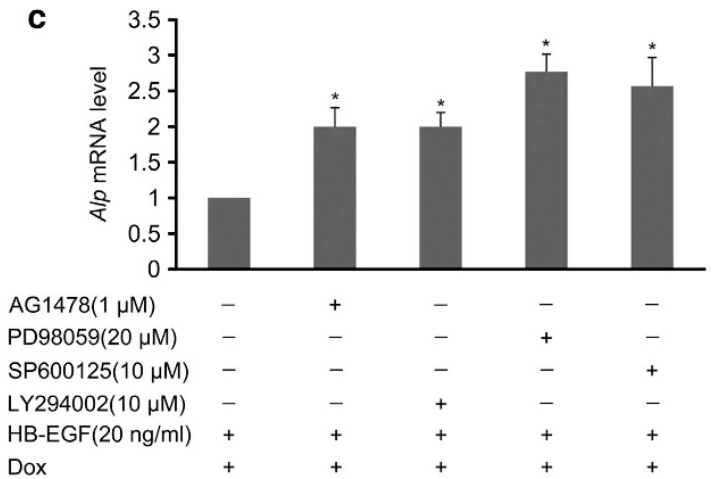

Figure 3 HB-EGF inhibits Runx2-induced early osteoblast differentiation using multiple signaling pathways. (a) C2C12/Runx $2^{\text {Dox }}$ cells were treated with HB-EGF and Dox for the times indicated and collected for protein extraction. The phosphorylation of EGFR, ERK, JNK, and Akt was determined by western blot analysis with the respective antibodies as described in Materials and Methods. (b) C2C12/Runx2 ${ }^{\text {Dox }}$ cells were pretreated with AG1478, PD98059, SP600125, or LY294002 for $1 \mathrm{~h}$. The cells were then treated with HB-EGF and Dox for 2 min and collected for protein extraction. The western blot analysis was performed as described in (a). (c) C2C12/Runx $2^{\text {Dox }}$ cells were pretreated with the indicated inhibitors as shown in (b) for $1 \mathrm{~h}$. The cells were then treated with HB-EGF and Dox for 3 days, and the mRNA level of Alp was determined by realtime qPCR analysis. Data are presented as mean \pm S.D. $(n=3)$. ${ }^{*} P<0.05$ compared with Dox- and HB-EGF-treated cells

Runx2 function, ${ }^{26-28}$ we concluded that the inhibition of Runx2-induced osteogenic differentiation by HB-EGF is at least partially mediated through repression of Runx2 function via regulation of Shn3, Twist2, and Maf.

miR-1192 directly targets $\mathbf{H b e g f}$ through translational inhibition. We hypothesized that inhibition of HB-EGF expression by Runx2 might be mediated through miRNA. Thus, we performed bioinformatics analysis using miRanda, ${ }^{29}$ miRWalk, $^{30}$ and TargetScan $^{31}$ programs, and identified several miRNAs, such as miR-1192, miR-27b-3p, miR-466f-3p, miR-532-3p, miR-132-3p, miR-212-3p, and miR-495-3p, that could potentially bind Hbegf $3^{\prime}$-UTR through multiple binding sites. To examine whether these miRNAs are regulated during Runx2-induced osteogenic differentiation of $\mathrm{C} 2 \mathrm{C} 12$ cells, we detected their expression levels in Dox-treated cells, and found that the expression of miR-1192 was upregulated (Figure 5a). In contrast, the expression of miR-132-3p, miR-212-3p, and miR-495-3p was not changed (data not shown), and the expression of miR-27b-3p, miR-466f-3p, and miR-532-3p was downregulated (Figure 5b). Thus, we focused our attention on miR-1192.

To evaluate the effect of miR-1192 on Runx2-induced osteogenic differentiation, we transfected miR control, miR1192, anti-miR control, and anti-miR-1192 into C2C12/ Runx $2^{\text {Dox }}$ cells, respectively, and found that transfection of miR-1192 increased the expression of $A / p$ and $O C$ (Figure $5 \mathrm{c}$ ), whereas transfection of anti-miR-1192 reduced their expression levels (Figure 5d). Moreover, ALP activity was increased in miR-1192-transfected cells (Figure 5e). These findings suggest that miR-1192 synergistically potentiates Runx2-induced osteogenic differentiation. Collectively, our results reveal that upregulated miR-1192 and downregulated HB-EGF exert opposite effect on Runx2-induced osteogenic differentiation, suggesting that miR-1192 could be the suppressor of HB-EGF during this differentiation process.

According to in silico analysis, Hbegf has two potential binding sites for miR-1192 within its $3^{\prime}$-UTR (Figure 6a). 
a $\frac{24 \mathrm{~h}}{\text { Hbegf } \mathrm{pcDNA3} .1} \frac{72 \mathrm{~h}}{\text { Hbegf pcDNA3.1 }}$

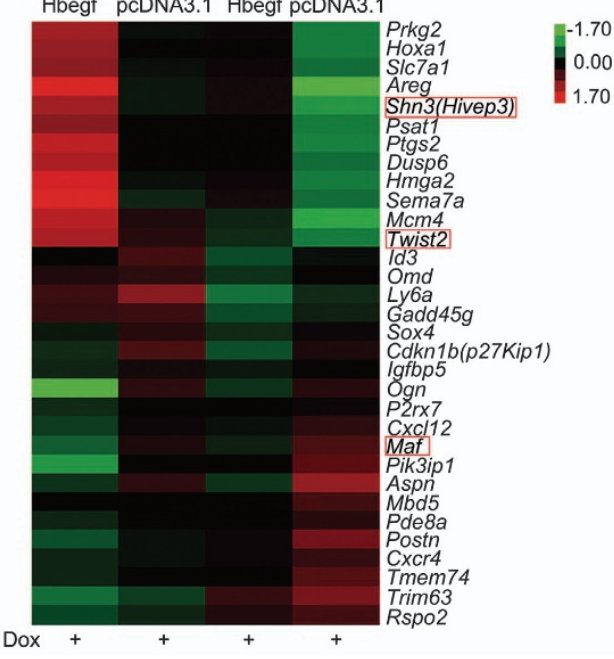

b

C

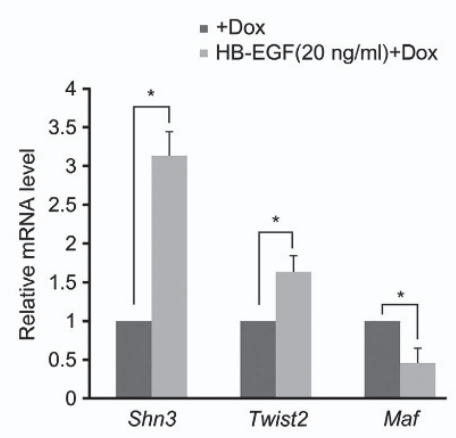

Figure 4 HB-EGF upregulates Shn3 and Twist2 but downregulates Maf mRNA levels. (a) Heat map showing the fold change for 32 genes that HB-EGF upregulated or downregulated by $\geq 1$.4-fold both on days 1 and 3 . The expression of these genes was validated by real-time qPCR analysis. (b) $\mathrm{C} 2 \mathrm{C} 12 /$ Runx $^{\text {Dox }}$ cells were treated with HBEGF and Dox for 3 days, and the expression of Shn3, Twist2, and Maf was determined by real-time qPCR analysis. Data are presented as mean \pm S.D. $(n=3)$. ${ }^{*} P<0.05$ compared with Dox-treated cells. (c) C2C12/Runx $2^{\text {Dox }}$ cells were pretreated with the indicated inhibitors as shown in Figure $3 \mathrm{~b}$ for $1 \mathrm{~h}$. The cells were treated with HB-EGF and Dox for 3 days and subjected to real-time qPCR analysis for Shn3, Twist2, and Maf mRNA. Data are presented as mean \pm S.D. $(n=3)$. ${ }^{*} P<0.05$, ${ }^{\star \star} P<0.01$ compared with HB-EGF- and Dox-treated cells

To investigate whether Hbegf can be directly targeted by miR1192, we engineered a luciferase reporter that has wild-type $3^{\prime}$-UTR of Hbegf (Figure 6b). Co-transfection of the Hbegf $3^{\prime}$-UTR luciferase reporter with miR-1192 resulted in downregulation of the luciferase activity compared with the miR control (Figure 6c). In comparison, miR-1192-Mut had no effect on Hbegf $3^{\prime}$-UTR luciferase reporter (Figure 6c), implying that Hbegf is a direct target of miR-1192. Thus, we further examined how miR-1192 repressed HB-EGF expression. Real-time qPCR result revealed no significant change in Hbegf mRNA level when miR-1192 was transfected into C2C12/Runx2 ${ }^{\text {Dox }}$ cells (Figure 6d). However, western blot result showed reduced HB-EGF protein level in the miR-1192-transfected cells compared with miR control sample (Figure 6e), indicating that miR-1192 mediates translational repression but not mRNA degradation of $\mathrm{Hbegf}$. Taken together, these results indicate that miR-1192 directly targets Hbegf through translational inhibition.

Transcriptional regulation of Hbegf by Runx2. As Hbegf mRNA level is significantly downregulated during Runx2induced osteogenic differentiation (Figure 2a), we wondered whether Runx2 could mediate Hbegf mRNA downregulation through direct binding to its promoter. To test this hypothesis, we first examined the proximal 1-kb promoter region of Hbegf to search for the putative Runx2-binding site using TFSEARCH database ${ }^{32}$ and ConSite program, ${ }^{33}$ and identified a site at -639 to -631 (site I, Runx2-I) (Figure 7a). With an electrophoretic mobility shift assay (EMSA), a labeled oligonucleotide containing Runx2-I produced a significant shift (BS) in the Dox-treated cells nuclear extract (Figure $7 \mathrm{~b}, \mathrm{BS}$ in lane 1). In contrast, no shift was produced in the extract from non-treated cells (Figure $7 \mathrm{~b}$, lane 8 ). The observed shift was abolished by 10 - to 50 -fold molar excess of unlabeled oligonucleotides (Figure 7b, lanes 2-4). The labeled oligonucleotide that contained a $9 \mathrm{bp}$ mutation also abolished the shift (Figure 7b, lane 7). Furthermore, the anti-Flag antibody, not the mouse IgG antibody, supershifted the complex (BS) (Figure 7b, lanes 5 and 6), suggesting the specificity of the interaction. Thus, the EMSA assay demonstrated that the Hbegf promoter contains one Runx2binding site, Runx2-I.

Chromatin immunoprecipitation (ChIP) assay was performed to examine whether Runx2 interacts with Hbegf promoter in vivo. In this ChIP assay, two pairs of primers were designed. Primer-1 was designed to amplify a $137 \mathrm{bp}$ fragment of the Hbegf promoter flanking the Runx2-I site, and primer-2 was designed to amplify a $157 \mathrm{bp}$ fragment of the Hbegf $3^{\prime}$-UTR in the absence of any potential Runx2-binding site. As shown in Figure 7c, the anti-Flag antibody specifically enriched the regions containing Runx2-I (primer-1). By contrast, no positive signals were detected in various negative controls, including the PCR control $\left(\mathrm{H}_{2} \mathrm{O}\right)$ or immunoprecipitation control. In addition, Runx2 did not associate with the Hbegf $3^{\prime}$-UTR (primer-2). These results indicate that Runx2 binds to the Hbegf promoter in vivo. Taken together, these results suggest that Runx2 acts as a transcriptional repressor on Hbegf.

\section{Discussion}

In the current study, we provided evidence for HB-EGF-EGFR signaling to be a negative regulator of Runx2-induced osteogenic differentiation, and demonstrated inactivation of HB-EGF-EGFR signaling by Runx2 through the downregulation of HB-EGF. Our data showed that miR-1192, a Runx2upregulated miRNA, promotes Runx2-induced osteogenic differentiation by targeting Hbegf. Furthermore, we found that 

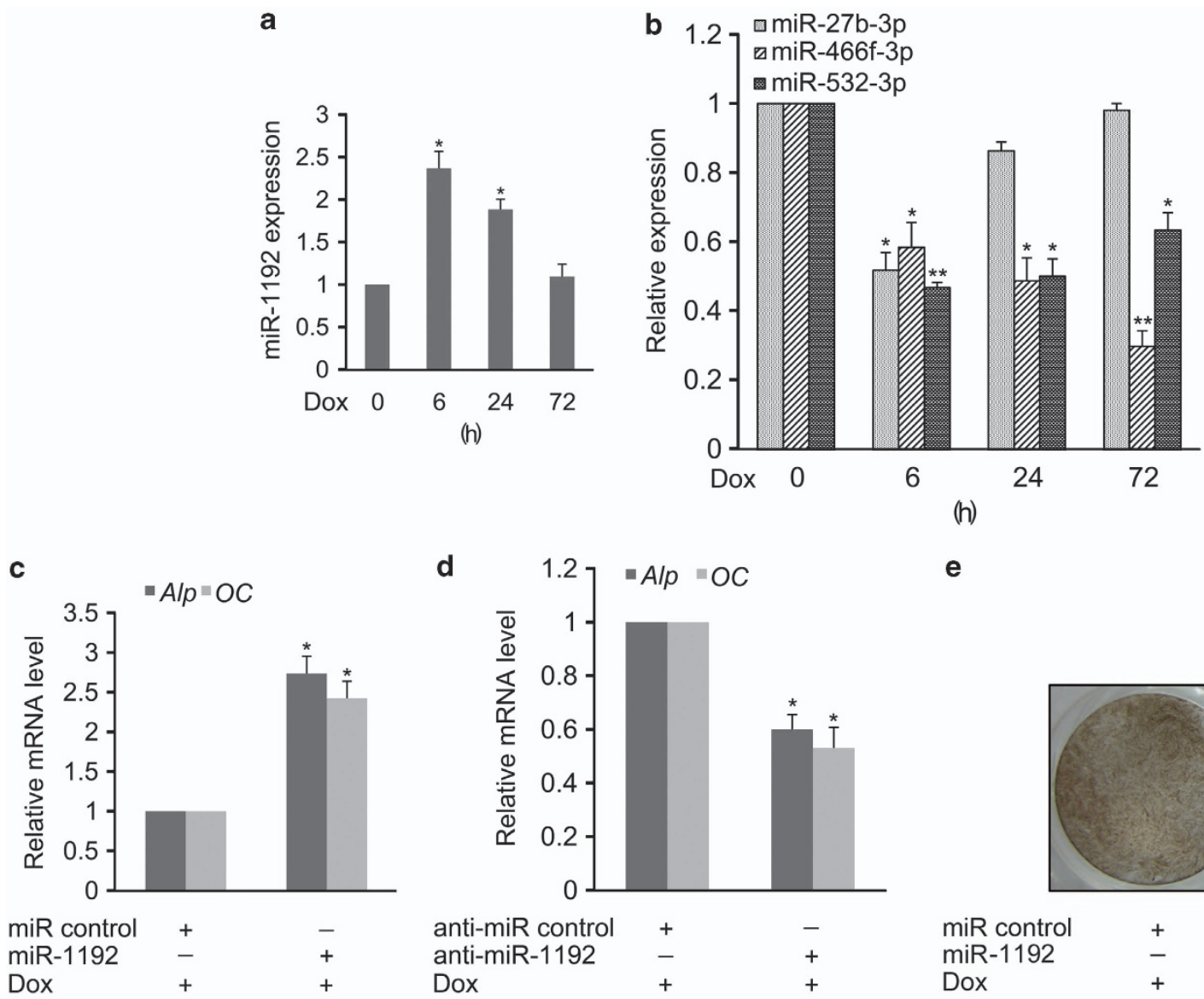

(h)

e

Figure 5 miR-1192 potentiates Runx2-induced osteogenic differentiation. (a and b) Real-time qPCR results of miR-1192 (a), miR-27b-3p (b), miR-466f-3p (b), and miR532-3p (b) in Dox-treated cells. Data are presented as mean \pm S.D. $(n=3) .{ }^{*} P<0.05,{ }^{\star \star} P<0.01$ compared with untreated cells $(0 \mathrm{~h})$. (c and d) Effect of miR-1192 on the expression of osteoblastic markers. C2C12/Runx $2^{\text {Dox }}$ cells were transfected with miR control (c), miR-1192 (c), anti-miR control (d), and anti-miR-1192 (d), respectively, and then treated with Dox for 3 days. The mRNA level of Alp and OC was determined by real-time qPCR analysis. Data are presented as mean \pm S.D. $(n=3)$. ${ }^{\star} P<0.05$ compared with miR control or anti-miR control samples. (e) Effect of miR-1192 on ALP activity. C2C12/Runx2 $2^{\text {Dox }}$ cells were transfected with miR control and miR-1192, respectively, and then treated with Dox for 7 days. The ALP activity was measured by ALP staining. Similar results were obtained in three independent experiments

Hbegf transcription is inhibited by Runx2 through direct binding to its promoter. These findings suggest that Runx2 induces osteogenic differentiation of $\mathrm{C} 2 \mathrm{C} 12$ cells by inactivating HB-EGF-EGFR signaling through the downregulation of HB-EGF via both transcriptional and post-transcriptional mechanisms.

We identified a novel Runx2-regulated miRNA (miR-1192), which was also upregulated during BMP-2-induced osteogenesis (Supplementary Figure S5). MiR-1192 expression was rapidly induced following activation of Runx2 (Figure 5a), and five potential Runx2-binding sites were identified in the $-2 \mathrm{~kb}$ genomic sequence upstream of the mir-1192 stem loop (Supplementary Figure S6), suggesting that miR-1192 may be a direct target of Runx2. Overexpression of miR-1192 promotes Runx2-induced early and late osteoblast differentiation, whereas knockdown of miR-1192 led to the opposite effect (Figures 5c-e). HB-EGF inhibits Runx2-induced early osteoblast differentiation (Figures $2 b-d$ ), and Hbegf is directly targeted by miR-1192 (Figure 6). These results indicate that miR-1192 exerts its effect on Runx2-induced early osteoblast differentiation through the downregulation of $\mathrm{HB}$ EGF. Because myoblastic $\mathrm{C} 2 \mathrm{C} 12$ cells have the capacity to differentiate into other mesoderm-type lineages (e.g., osteoblasts, chondroblasts, and adipocytes), it is therefore possible that other undisclosed miR-1192 targets, which are involved in pluripotency (e.g., Rbbp4), ${ }^{34}$ myogenesis (e.g., $R b 1 c c 1$ and Cdc42), ${ }^{35,36}$ and osteogenesis (e.g., Nrf2 and Tbx3), ${ }^{37,38}$ may contribute to the effect of miR-1192 on Runx2-induced late osteoblast differentiation.

We demonstrated that miR-1192 mediates translational repression but not mRNA degradation of Hbegf (Figures 6d and e). However, the mRNA level of Hbegf was downregulated during Runx2-induced osteogenesis (Figure 2a). It is therefore possible that $\mathrm{Hbegf}$ transcription is regulated by Runx2. We first confirmed that Runx2 binds to the Hbegf promoter (Figure 7), indicating that Hbegf transcription is directly repressed by Runx2. Furthermore, Hbegf trancription can be directly activated by some transcription factors (e.g., NF-Kappa B). ${ }^{39}$ We found that Runx2 inhibits expression of members of the NF- $\kappa$ B family (Supplementary Figure S7), suggesting the indirect negative regulation of Hbegf transcription by Runx2. In addition, miR-212 was reported to mediate $H B-E G F$ mRNA degradation, ${ }^{40}$ raising the possibility that the Hbegf mRNA level might be regulated by Runx2-regulated 


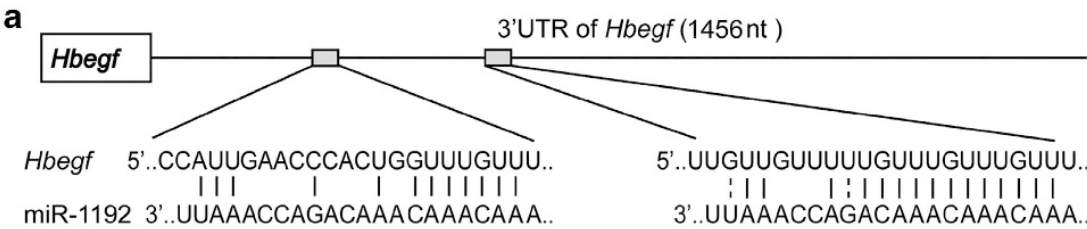

Position 271-293

Position 580-602

b

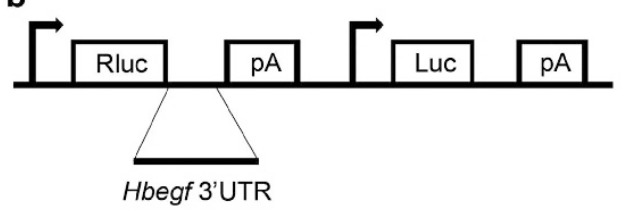

miR-1192 5'-AAACAAACAAACAGACCAAAUU-3'

miR-1192-Mut 5'-AUUGUUUGAAACAGACCAAAUU-3'

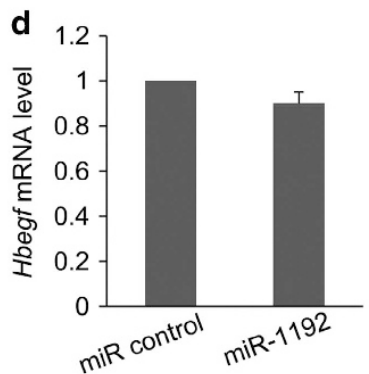

e

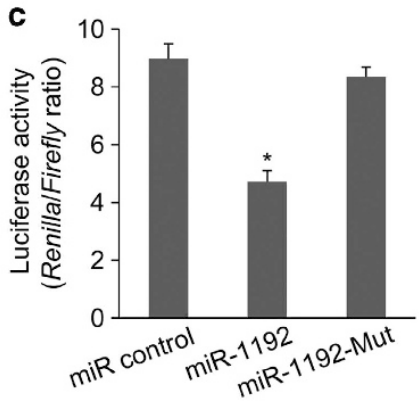

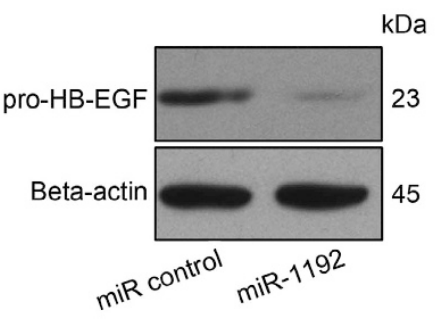

Figure 6 miR-1192 directly targets Hbegf. (a) Schematic representing miR-1192 target sites in Hbegf $3^{\prime}$-UTR and base pairing of miR-1192 sequences with the $3^{\prime}$-UTR. (b) Schematic diagram illustrating the design of luciferase reporter with Hbegf $3^{\prime}$-UTR. The sequences of miR-1192 and miR-1192-Mut are also shown. The underlined sequences represent wild-type and mutated seed sequences of miR-1192. Rluc, Renilla luciferase; Luc, Firefly luciferase; pA, polyadenylation signal. (c) miR control, miR1192, or miR-1192-mut was co-transfected with psiCHECK-2-Hbegf $3^{\prime}$-UTR reporter into C2C12/Runx2 ${ }^{\text {Dox }}$ cells. After $48 \mathrm{~h}$, cells were harvested and luciferase activities were measured. Luciferase activity $=($ Renilla/Firefly) ratio. Renilla, raw renilla luciferase activity; Firefly, firefly luciferase activity. Data are presented as mean \pm S.D. ( $n=3$ ).

${ }^{*} P<0.05$ compared with miR control sample. (d and e) Relative mRNA level of Hbegf (d) and protein level of pro-HB-EGF (e) in miR control- or miR-1192-transfected cells

miRNAs through mRNA degradation. Taken together, the mRNA level of Hbegf might be regulated by Runx2 through both transcriptional and post-transcriptional mechanisms.

In fact, HB-EGF is a positive regulator of myogenic differentiation of $\mathrm{C} 2 \mathrm{C} 12$ cells and act as a survival factor in skeletal myotubes, ${ }^{25,41}$ supporting the observations that Hbegf was significantly downregulated during Runx2-induced osteogenesis (Figure 2a), and that this differentiation process was inhibited by HB-EGF overexpression or HB-EGF treatment (Figures $2 b-d$ ). The effect of HB-EGF on osteogenesis was also observed during BMP-2-induced osteogenic differentiation of $\mathrm{C} 2 \mathrm{C} 12$ cells (Supplementary Figure S8). Nakamura et al. ${ }^{20}$ and Zhu et al. ${ }^{42}$ have demonstrated the negative effect of HB-EGF in osteogenic differentiation of MC3T3 and mouse bone marrow primary osteoblastic cells. Taken together, these data suggest the general role of HB-EGF-mediated signaling in the inhibition of osteogenic differentiation, and that Runx2 might be the key factor for relieving the negative effect of HB-EGF during osteogenesis.

To study the mechanism by which HB-EGF inhibits Runx2-induced osteogenic differentiation, we searched for HB-EGF-regulated genes that have an established function in regulating osteogenesis using mRNA profiling. Three genes, Shn3, Twist2, and Maf, were successfully identified
(Figure 4a). Shn3 was reported to decrease Runx2 protein stability in a ubiquitin-proteasome-dependent manner, ${ }^{27}$ whereas Twist2 and Maf were demonstrated to modulate Runx2 transcriptional activity. ${ }^{26,28}$ Nakamura et al. ${ }^{20}$ and Zhu et $a .^{42}$ have provided evidence that HB-EGF-mediated signaling decreases Runx2 transcriptional activity. Our data revealed that HB-EGF treatment results in reduced level of Runx2 protein in a time-dependent manner (Supplementary Figure S9), possibly resulting from the upregulation of Shn3. Thus, we proposed that HB-EGF-mediated signaling could repress Runx2 function by promoting its degradation and inhibiting its transcriptional activity (Supplementary Figure S10). In addition, because Runx2 possesses a G1-related antiproliferative function in different mesenchymal cell types (e.g., C2C12 and MC3T3 cells), ${ }^{43}$ and ST2 cells proliferation is inhibited during Runx2-induced osteogenic differentiation, ${ }^{23}$ and HB-EGF-EGFR signaling enhances MC3T3 cells proliferation through the upregulation of $p 27,{ }^{20}$ it is therefore possible that relief of Runx2-induced inhibition of $\mathrm{C} 2 \mathrm{C} 12$ cells proliferation might also be essential for HB-EGF-mediated signaling to block Runx2-induced osteogenic differentiation. This effect of HB-EGF might depend on the regulating expression of genes involved in cell proliferation (e.g., p27Kip1, Mcm4, and Areg) (Figure 4a). 

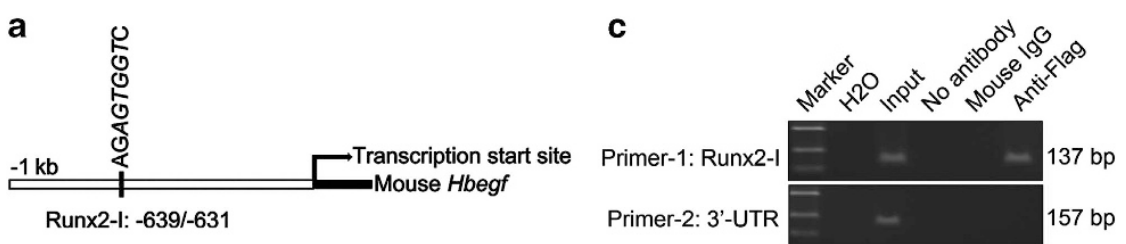

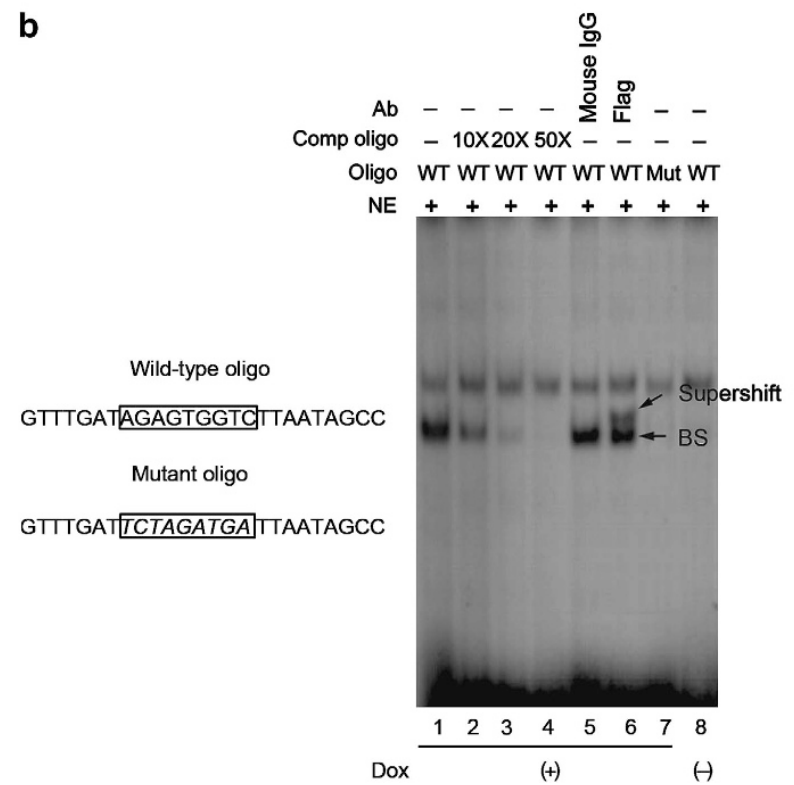

Figure $7 \quad H b e g f$ is directly regulated by Runx2. (a) Schematic representation of mouse Hbegf genomic locus, which indicates the locations of $H b e g f$ site (Runx2-I). The italic letters indicate the core sequence of each site. (b) EMSA shows the interaction between Hbegf site (Runx2-I) and Runx2 in Dox-treated cells. The bottom arrow indicates the DNA-protein complex (BS). The top arrow indicates the Runx2-supershifed complex. WT, wild-type; Mut, mutant; NE, nuclear extract; Ab, antibody; Oligo, oligonucleotide; Comp oligo, competitor oligonucleotide. (c) ChIP analysis was performed to confirm the interaction of Runx2 with Hbegf promoter in vivo. PCR was performed with primer-1, which was designed to amplify a fragment of the Hbegf promoter flanking the Runx2-I site. The primer-2 for a nonspecific region locating the Hbegf $3^{\prime} U T R$ was utilized for the control reaction in this ChIP analysis

In conclusion, the newly described miR-1192 has an important role in Runx2-induced osteogenesis, and can be referred to as 'osteomiR'. We also presented a concept that there is a Runx2/miR-1192/HB-EGF regulatory loop during osteogenesis (Supplementary Figure S10). Our findings provide new insight into the mechanism of regulation of osteoblast differentiation and bone formation by Runx2, and may support the clinical application of Runx2-induced osteogenesis for therapeutic treatment of osseous defects.

\section{Materials and Methods}

Materials. The $\mathrm{C}_{2} \mathrm{C} 12, \mathrm{MC} 3 \mathrm{~T} 3$, and $\mathrm{C} 3 \mathrm{H} 10 \mathrm{~T} 1 / 2$ cells were purchased from American Type Culture Collection (ATCC, Manassas, VA, USA). Hygromycin B, G418, and Prolong Gold Antifade Reagent with 4', 6-diamidino-2-phenylindole (DAPI) were purchased from Invitrogen (Carlsbad, CA, USA). Dox- and Tet System-Approved FBS were purchased from Clontech (Mountain View, CA, USA). Mouse anti-Flag M2 monoclonal antibody and normal mouse immunoglobulin $G$ (IgG) were purchased from Sigma (St Louis, MO, USA). The anti-pro-HB-EGF antibody was purchased from Santa Cruz Biotechnology (Santa Cruz, CA, USA). Anti-EGFR, anti-phospho-EGFR (Tyr1068), anti-ERK1/2, anti-phospho-ERK1/2 (Thr202/Tyr204), anti-JNK1/2, anti-phospho-JNK1/2(Thr183/Tyr185), anti-Akt, antiphospho-Akt (Ser473), anti- $\beta$-actin, and Alexa Fluor 555-conjugated $F\left(a^{\prime}\right) 2$ fragment of goat anti-mouse $\operatorname{lgG}(\mathrm{H}+\mathrm{L})$, AG1478, PD98059, and LY294002 were purchased from Cell Signaling Technology (Beverly, MA, USA). SP600125 was purchased from Calbiochem (Los Angeles, CA, USA). HB-EGF and BMP-2 were purchased from R\&D Systems (Minneapolis, MN, USA). miR control, miR-1192 mimic, miR-1192-Mut (mimics containing a mutated miR-1192 seed sequence),
anti-miR control, and anti-miR-1192 were purchased from Ambion (Austin, TX, USA).

Cell culture. The establishment of $\mathrm{C} 2 \mathrm{C} 12 / \mathrm{Run} \times 2^{\mathrm{Dox}}$ subline has been described previously. ${ }^{44}$ C2C12/Runx $2^{\text {Dox }}$ cells were maintained in Dulbecco's modified Eagle's medium (DMEM) supplemented with 10\% Tet System-

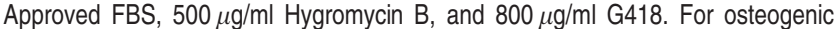
differentiation, C2C12/Runx $2^{\text {Dox }}$ cells were cultured in medium containing Dox $(10 \mu \mathrm{g} / \mathrm{ml})$.

Plasmid construction. psiCHECK-2 vector (Promega, Madison, WI, USA) was initially designed to provide a quantitative and rapid approach for optimization of RNA interference, and this vector can also be used to screen for miRNA targets. Detailed information about this vector can be obtained from the siCHECK Vectors Protocol (Promega; literature no. TB329). A 881-bp fragment of the Hbegf $3^{\prime}$-UTR containing miR-1192 target sites was amplified from mouse genomic DNA. Amplicon was cleaved with Sgfl and Notl (MBI Fermentas, Burlington, ON, Canada) and cloned in between the Sgfl and Notl cleavage sites of psiCHECK-2 vector (Promega) downstream of the Renilla luciferase reporter gene. The cDNA encoding mouse full-length Runx2, HB-EGF, and Ereg were obtained by PCR and cloned into the expression vector pcDNA3.1 (Invitrogen). The inserted sequences were further confirmed through DNA sequencing. The primers used for plasmid construction were listed in the Supplementary Tables S1 and 2.

In vitro osteoblastogenesis and cell staining. $\mathrm{C} 2 \mathrm{C} 12 / \mathrm{Run}^{\mathrm{D}} 2^{\mathrm{Dox}}$ cells were cultured in DMEM containing Dox, $\beta$-glycerophosphate disodium $(10 \mathrm{mM})$ and ascorbic acid $(50 \mu \mathrm{g} / \mathrm{ml})$. The medium was changed every 3 days. For ALP and Alizarin Red staining, the detailed procedures were described previously. $^{20,45}$ 
Reverse transcription-PCR. Total RNA was extracted by Trizol reagent (Invitrogen). A $20 \mu \mathrm{l}$ reaction mixture containing $2 \mu \mathrm{g}$ of total RNA was reversely transcribed to cDNA using RT Ace reverse transcriptase (Toyobo, Osaka, Japan). Real-time qPCR was performed on the CDNA to examine the expression levels of mRNAs and miRNAs. The PCR reaction mix was prepared using SYBR Green PCR Master Mix (Takara, Shiga, Japan). PCR conditions were as follows: $95^{\circ} \mathrm{C}$ for $30 \mathrm{~s}, 40$ cycles of denaturation at $95^{\circ} \mathrm{C}$ for $5 \mathrm{~s}$, annealing at $60^{\circ} \mathrm{C}$ for $30 \mathrm{~s}$, and extension at $72^{\circ} \mathrm{C}$ for $15 \mathrm{~s}$. PCR was carried out using the Real-Time PCR Detection System Rotor-Gene 6000 (Corbett Research, Mortlake, NSW, Australia). The fluorescence of each sample was determined after every cycle. Denaturation curves of PCR products were determined by increasing temperature at the rate of $0.1^{\circ} \mathrm{C} / \mathrm{min}$ from $55^{\circ} \mathrm{C}$ to $95^{\circ} \mathrm{C}$. Fluorescence of samples was continuously traced during this period. All of the melting curves of PCR products gave single peaks. Agarose gel electrophoresis of representative reactions was used to confirm amplification of unique fragments of predicted lengths. Relative expression levels were calculated as ratios normalized against those of 18S rRNA or U6 snRNA. The data from real-time qPCR were analyzed by the $\triangle \mathrm{Ct}$ method, and the $\triangle \mathrm{Ct}$ value was determined by subtracting the 18S rRNA Ct value from the target gene $\mathrm{Ct}$ value or the $\mathrm{U} 6$ snRNA Ct value from the target miRNA Ct value. The $\Delta \mathrm{Ct}$ of the treated cells ( $\Delta \mathrm{Cts})$ was subtracted from the $\Delta \mathrm{Ct}$ of the untreated cells ( $\Delta \mathrm{Ctu})(\Delta \Delta \mathrm{Ct}=\Delta \mathrm{Cts}-\Delta \mathrm{Ctu})$, and the expression level for a target gene or miRNA in the treated cells compared with the level in the untreated cells was calculated as follows: $x$-fold of untreated control $=2^{-\Delta \Delta C t}$. The primers used for reverse transcription-PCR (RT-PCR) were listed in Supplementary Tables S3-S5.

Western blot analysis. Cells were washed with PBS and lysed with mammalian protein extraction reagent from M-PER (Thermo Fisher Scientific, Waltham, MA, USA) supplemented with protease inhibitor mixture tablet (Roche, Indianapolis, IN, USA). Protein concentrations were determined by BCA protein assay (Thermo Fisher Scientific). Proteins, $30-50 \mu \mathrm{g}$, were resolved by $12 \%$ SDS-PAGE gel and transferred to polyvinylidene fluoride membranes (Millipore, Bedford, MA, USA) at $100 \mathrm{~V}$ for $2 \mathrm{~h}$ on ice. Membranes were blocked with $5 \%$ non-fat milk in Tris-buffered saline (TBS, $\mathrm{pH}$ 7.4) for $1 \mathrm{~h}$ at room temperature and incubated with primary antibody diluted in $2 \%$ non-fat milk in TBS $(0.1 \%$ Tween-20) at $4{ }^{\circ} \mathrm{C}$ for $2 \mathrm{~h}$. Membranes were washed with TBS (0.1\% Tween-20) and then incubated with second antibody conjugated to horseradish peroxidase in $2 \%$ non-fat milk in TBS at $4{ }^{\circ} \mathrm{C}$ for $1 \mathrm{~h}$. After washing with TBS $(0.1 \%$ Tween-20), signal intensity was visualized by enhanced chemiluminescence system (PerkinElmer Life and Analytical Sciences, Waltham, MA, USA) and recorded on X-ray films (Fuji, Tokyo, Japan). $\beta$-Actin was used as a loading control. The primary antibodies used in this study were listed in Materials and Methods.

Immunofluorescence. Cells were washed with PBS, then fixed with $4 \%$ formaldehyde in PBS for $20 \mathrm{~min}$, and finally permeabilized with $0.2 \%$ Triton X-100 solution for $5 \mathrm{~min}$. Cells were incubated with anti-Flag antibody for $1 \mathrm{~h}$, washed three times with PBS, and then incubated with appropriate Alexa Fluor 555conjugated secondary antibody and washed again three times in PBS. Coverslips were mounted with ProLong Gold antifade reagent with DAPI, and examined using a Leica fluorescence microscope (Leica, Wetzlar, Germany).

Transfection and luciferase assay. MiR-1192 and miR control were transfected at $50 \mathrm{nM}$ concentration with Lipofectamine 2000 (Invitrogen) into C2C12/Runx2 $2^{\text {Dox }}$ cells at $50 \%$ confluence. Cells were harvested at $48 \mathrm{~h}$ after transfection to perform protein and mRNA analyses. For luciferase activity assay, miR-1192, miR-1192-Mut, or miR control was co-transfected with psiCHECK-2Hbegf reporter into C2C12/Runx $2^{\text {Dox }}$ cells using Lipofectamine 2000 . After $48 \mathrm{~h}$, Firefly and Renilla luciferase activity were measured in cell lysates using a DualLuciferase Reporter Assay System (Promega) on a Fusion plate reader (PerkinElmer Life and Analytical Sciences). Firefly luciferase activity was used for normalization and as an internal control for transfection efficiency.

mRNA profiling analysis. Briefly, $5 \mu \mathrm{g}$ of total RNA was used to synthesize double-stranded CDNA by using the SuperScript II System (Invitrogen) in combination with a T7-oligo(dT) primer (Ambion). The cDNA was used as a template for the preparation of biotin-labeled CRNA using the GeneChip IVT Labeling Kit (Affymetrix, Santa Clara, CA, USA). Subsequently, $10 \mu \mathrm{g}$ of biotinylated cRNA was hybridized to the Affymetrix GeneChip mouse genome 430 2.0 array obtained from CapitalBio Corp. (Beijing, China). Finally, GeneChip
Scanner 3000 and GeneChipOperating Software (GCOS) v.1.1.1 (Affymetrix) were used to scan images. The median value of each microarray was normalized to 500 .

Electrophoretic mobility shift assay. Nuclear extracts were prepared from C2C12/Runx $2^{\text {Dox }}$ cells treated with Dox according the manufacturer's instructions (Active Motif, Carlsbad, CA, USA). Aliquots of the supernatant were harvested and stored at $-80^{\circ} \mathrm{C}$. Protein concentrations were determined using the BCA protein assay reagent (Thermo Fisher Scientific). EMSA was performed using the EMSA kit (Promega). Nuclear extract proteins $(5.0 \mu \mathrm{g})$ were incubated in a $15 \mu \mathrm{l}$ reaction containing $4 \%$ glycerol, $1 \mathrm{mM} \mathrm{MgCl}_{2}, 0.5 \mathrm{mM}$ dithiothreitol, $0.5 \mathrm{mM}$ EDTA, $50 \mathrm{mM} \mathrm{NaCl}, 10 \mathrm{mM}$ Tris- $\mathrm{HCl}, \mathrm{pH} 7.5$, and $2.0 \mu \mathrm{g}$ poly-(dl-dC) with or without a molar excess of unlabeled oligonucleotide on ice for $15 \mathrm{~min}$ following the addition of the labeled oligonucleotide. For supershift assays, an antibody against Flag-Runx2 (anti-Flag antibody) or normal mouse IgG was added to the reaction mixture and incubated $25 \mathrm{~min}$ before the addition of the labeled oligonucleotide. All DNA-protein complexes were resolved by electrophoresis on $5 \%$ native polyacrylamide gels. The double-stranded oligonucleotides used in EMSA were depicted in Supplementary Table S6.

ChIP assay. Briefly, C2C12/Runx $2^{\text {Dox }}$ cells were treated with Dox. A total of $2 \times 10^{6}$ cells were exposed to $1 \%$ formaldehyde in DMEM for $10 \mathrm{~min}$ at $37^{\circ} \mathrm{C}$. Glycine was added to $0.125 \mathrm{M}$, and the cultures were incubated for $2 \mathrm{~min}$. The cells were collected in cold PBS, pelleted by centrifugation, and lysed in buffer. Lysed samples were sonicated to obtain DNA fragments whose lengths range from 500 to $1000 \mathrm{bp}$, and the lysates were pelleted and precleared. Precleared chromatin was incubated with $2 \mu \mathrm{g}$ of the anti-Flag antibody or normal mouse IgG and rotated at $4{ }^{\circ} \mathrm{C}$ for $12 \mathrm{~h}$. The protein-DNA complexes were incubated with protein $\mathrm{G}$ beads. The protein-DNA complexes were eluted with buffer containing $1 \% \mathrm{SDS}$ and $0.1 \mathrm{M} \mathrm{NaHCO}_{3}$, and crosslinks were reversed at $65^{\circ} \mathrm{C}$. DNA was recovered by phenol-chloroform extraction and ethanol precipitation and then subjected to PCR analysis. Amplified products were electrophoresed through $2 \%$ agarose gel and visualized by Goldview staining. The primers used in ChIP assay were listed in Supplementary Table S7.

Statistical analysis. Data are presented as mean \pm S.D. Comparisons were made by using a two-tailed $t$-test or one-way ANOVA for experiments with more than two subgroups. A $P$-value of $<0.05$ was considered statistically significant.

\section{Display items}

(1) Runx2 inhibits myogenic differentiation and induces osteoblast differentiation in C2C12 cells.

(2) HB-EGF inhibits Runx2-induced early osteoblast differentiation of $\mathrm{C} 2 \mathrm{C} 12$ cells.

(3) HB-EGF inhibits Runx2-induced early osteoblast differentiation using multiple signaling pathways.

(4) HB-EGF upregulates Shn3 and Twist2 but downregulates Maf mRNA levels.

(5) miR-1192 potentiates Runx2-induced osteogenic differentiation.

(6) miR-1192 directly targets Hbegf.

(7) Hbegf is directly regulated by Runx2.

\section{Conflict of Interest}

The authors declare no conflict of interest.

Acknowledgements. This work was supported by National Natural Science Foundation of China (Grant Nos. 90919050, 81071524, 81171778, 31171086, and 30971466).

\section{Author Contributions}

SY and QG: conception and design, collection and assembly of data, data analysis and interpretation, and manucript writing; both authors contributed equally to this work; JM: collection and/or assembly of data, data analysis, and interpretation; FS: conception and design, data analysis, and interpretation; YY: collection and/or assembly of data; QP: data analysis and interpretation, and administrative support; 
$\mathrm{AH}$ : conception and design, data analysis and interpretation,manuscript writing, and financial support of manuscript.

1. Komori T. Regulation of skeletal development by the Runx family of transcription factors. $J$ Cell Biochem 2005; 95: 445-453.

2. Otto F, Thornell AP, Crompton T, Denzel A, Gilmour KC, Rosewell IR et al Cbfa1, candidate gene for cleidocranial dysplasia syndrome, is essential for osteoblast differentiation and bone development. Cell 1997; 89: 765-771.

3. Liu W, Toyosawa S, Furuichi T, Kanatani N, Yoshida C, Liu Y et al. Overexpression of Cbfa1 in osteoblasts inhibits osteoblast maturation and causes osteopenia with multiple fractures. J Cell Biol 2001; 155: 157-166.

4. Kobayashi H, Gao Y, Ueta C, Yamaguchi A, Komori T. Multilineage differentiation of Cbfa1-deficient calvarial cells in vitro. Biochem Biophys Res Commun 2000; 273: 630-636

5. Gersbach CA, Byers BA, Pavlath GK, García AJ. Runx2/Cbfa1 stimulates transdifferentiation of primary skeletal myoblasts into a mineralizing osteoblastic phenotype. Exp Cell Res 2004; 300: 406-417

6. Huang YF, Lin JJ, Lin $\mathrm{CH}$, Su Y, Hung SC. c-Jun N-terminal kinase 1 negatively regulates osteoblastic differentiation induced by BMP2 via phosphorylation of Runx2 at Ser104. J Bone Miner Res 2012; 27: 1093-1105.

7. Jeon EJ, Lee KY, Choi NS, Lee MH, Kim HN, Jin YH et al. Bone morphogenetic protein-2 stimulates Runx2 acetylation. J Biol Chem 2006; 281: 16502-16511.

8. Wang CY, Yang SF, Wang Z, Tan JM, Xing SM, Chen DC et al. PCAF acetylates Runx2 and promotes osteoblast differentiation. J Bone Miner Metab 2013; 31: 381-389.

9. Jun JH, Yoon WJ, Seo SB, Woo KM, Kim GS, Ryoo HM et al. BMP2-activated Erk/MAP kinase stabilizes Runx2 by increasing p300 levels and histone acetyltransferase activity. J Biol Chem 2010; 285: 36410-36419.

10. Zhao M, Qiao M, Harris SE, Oyajobi BO, Mundy GR, Chen D. Smurf1 inhibits osteoblas differentiation and bone formation in vitro and in vivo. J Biol Chem 2004; 279: 12854-12859.

11. Li X, Huang $M$, Zheng $H$, Wang $Y$, Ren $F$, Shang $Y$ et al. CHIP promotes Runx2 degradation and negatively regulates osteoblast differentiation. J Cell Biol 2008; 181: 959-972.

12. Li Z, Hassan MQ, Volinia S, van Wijnen AJ, Stein JL, Croce CM et al. A microRNA signature for a BMP2-induced osteoblast lineage commitment program. Proc Natl Acad Sci USA 2008; 105: 13906-13911.

13. Huang J, Zhao L, Xing L, Chen D. MicroRNA-204 regulates Runx2 protein expression and mesenchymal progenitor cell differentiation. Stem Cells 2010; 28: 357-364.

14. Zhang $Y$, Xie RL, Croce CM, Stein JL, Lian JB, van Wijnen AJ et al. A program of microRNAs controls osteogenic lineage progression by targeting transcription facto Runx2. Proc Natl Acad Sci USA 2011; 108: 9863-9868.

15. Hassan MQ, Gordon JA, Beloti MM, Croce CM, van Wijnen AJ, Stein JL et al. A network connecting Runx2, SATB2, and the miR-23a-27a-24-2 cluster regulates the osteoblast differentiation program. Proc Natl Acad Sci USA 2010; 107: 19879-19884.

16. Hu R, Liu W, Li H, Yang L, Chen C, Xia ZY et al. A Runx2/miR-3960/miR-2861 regulatory feedback loop during mouse osteoblast differentiation. J Biol Chem 2011; 286: 12328-12339.

17. Goishi K, Higashiyama S, Klagsbrun M, Nakano N, Umata T, Ishikawa M et al. Phorbo ester induces the rapid processing of cell surface heparin-binding EGF-like growth factor: conversion from juxtacrine to paracrine growth factor activity. Mol Biol Cell 1995; 6 967-980.

18. Miyamoto S, Yagi H, Yotsumoto F, Kawarabayashi T, Mekada E. Heparin-binding epidermal growth factor-like growth factor as a novel targeting molecule for cancer therapy. Cancer Sci 2006; 97: 341-347.

19. Jessmon P, Kilburn BA, Romero R, Leach RE, Armant DR. Function-specific intracellula signaling pathways downstream of heparin-binding EGF-like growth factor utilized by human trophoblasts. Biol Reprod 2010; 82: 921-929.

20. Nakamura T, Toita H, Yoshimoto A, Nishimura D, Takagi T, Ogawa T et al. Potential involvement of Twist2 and Erk in the regulation of osteoblastogenesis by HB-EGF-EGFR signaling. Cell Struct Funct 2010; 35: 53-61.

21. Krampera M, Pasini A, Rigo A, Scupoli MT, Tecchio C, Malpeli G et al. HB-EGF/HER-1 signaling in bone marrow mesenchymal stem cells: inducing cell expansion and reversibly preventing multilineage differentiation. Blood 2005; 106: 59-66.

22. Wang K, Yamamoto H, Chin JR, Werb Z, Vu TH. Epidermal growth factor receptor-deficien mice have delayed primary endochondral ossification because of defective osteoclast recruitment. J Biol Chem 2004; 279: 53848-53856.

23. Baniwal SK, Shah PK, Shi Y, Haduong JH, Declerck YA, Gabet Y et al. Runx2 promotes both osteoblastogenesis and novel osteoclastogenic signals in ST2 mesenchymal progenitor cells. Osteoporos Int 2012; 23: 1399-1413.
24. Zhao Z, Zhao M, Xiao G. Franceschi RT. Gene transfer of the Runx2 transcription factor enhances osteogenic activity of bone marrow stromal cells in vitro and in vivo. Mol Ther 2005; 12: 247-253.

25. Chen X, Raab G, Deutsch U, Zhang J, Ezzell RM, Klagsbrun M. Induction of heparinbinding EGF-like growth factor expression during myogenesis. Activation of the gene by MyoD and localization of the transmembrane form of the protein on the myotube surface. J Biol Chem 1995; 270: 18285-18294.

26. Bialek P, Kern B, Yang X, Schrock M, Sosic D, Hong N et al. A twist code determines the onset of osteoblast differentiation. Dev Cell 2004; 6: 423-435.

27. Jones DC, Wein MN, Oukka M, Hofstaetter JG, Glimcher MJ, Glimcher LH. Regulation of adult bone mass by the zinc finger adapter protein Schnurri-3. Science 2006; 312: 1223-1227.

28. Nishikawa K, Nakashima T, Takeda S, Isogai M, Hamada M, Kimura A et al. Maf promotes osteoblast differentiation in mice by mediating the age-related switch in mesenchymal cell differentiation. J Clin Invest 2010; 12: 3455-3465.

29. John B, Enright AJ, Aravin A, Tuschl T, Sander C, Marks DS. Human MicroRNA targets. PLoS Biol 2004; 2: e363.

30. Dweep H, Sticht C, Pandey P, Gretz N. miRWalk - database: prediction of possible miRNA binding sites by 'walking' the genes of three genomes. J Biomed Inform 2011; 44: 839-847.

31. Lewis BP, Shih IH, Jones-Rhoades MW, Bartel DP, Burge CB. Prediction of mammalian microRNA targets. Cell 2003; 115: 787-798.

32. Heinemeyer T, Wingender E, Reuter I, Hermjakob H, Kel AE, Kel OV et al. Databases on transcriptional regulation: TRANSFAC, TRRD and COMPEL. Nucleic Acids Res 1998; 26 : 362-367.

33. Sandelin A, Wasserman WW, Lenhard B. ConSite: web-based prediction of regulatory elements using cross-species comparison. Nucleic Acids Res 2004; 32: W249-W252.

34. O'Connor MD, Wederell E, Robertson G, Delaney A, Morozova O, Poon SS et al. Retinoblastoma-binding proteins 4 and 9 are important for human pluripotent stem cell maintenance. Exp Hematol 2011; 39: 866-879.

35. Watanabe R, Chano $T$, Inoue $H$, Isono $T$, Koiwai $O$, Okabe H. Rb1cc1 is critical for myoblast differentiation through Rb1 regulation. Virchows Arch 2005; 447: 643-648.

36. Kang JS, Bae GU, Yi MJ, Yang YJ, Oh JE, Takaesu G et al. A Cdo-Bnip-2-Cdc42 signaling pathway regulates p38alpha/beta MAPK activity and myogenic differentiation. $J$ Cell Biol 2008; 182: 497-507.

37. Hinoi E, Fujimori S, Wang L, Hojo H, Uno K, Yoneda Y. Nrf2 negatively regulates osteoblast differentiation via interfering with Runx2-dependent transcriptional activation. J Biol Chem 2006; 281: 18015-18024.

38. Deepak V, Zhang Z, Meng L, Zeng X, Liu W. Reduced activity and cytoplasmic localization of Runx2 is observed in C3h10t1/2 cells overexpressing Tbx3. Cell Biochem Funct 2011; 29: $348-350$.

39. Ornskov D, Nexo E, Sorensen BS. Insulin induces a transcriptional activation of epiregulin, HB-EGF and amphiregulin, by a PI3K-dependent mechanism: identification of a specific insulin-responsive promoter element. Biochem Biophys Res Commun 2007; 354: 885-891.

40. Hatakeyama H, Cheng H, Wirth P, Counsell A, Marcrom SR, Wood CB et al. Regulation of heparin-binding EGF-like growth factor by miR-212 and acquired cetuximab-resistance in head and neck squamous cell carcinoma. PloS One 2010; 5: e12702.

41. Horikawa M, Higashiyama S, Nomura S, Kitamura Y, Ishikawa M, Taniguchi N Upregulation of endogenous heparin-binding EGF-like growth factor and its role as a survival factor in skeletal myotubes. FEBS Lett 1999; 459: 100-104

42. Zhu J, Shimizu E, Zhang X, Partridge NC, Qin L. EGFR signaling suppresses osteoblast differentiation and inhibits expression of master osteoblastic transcription factors Runx2 and Osterix. J Cell Biochem 2011; 112: 1749-1760.

43. Galindo M, Pratap J, Young DW, Hovhannisyan H, Im HJ, Choi JY et al. The bone-specific expression of Runx2 oscillates during the cell cycle to support a G1-related antiproliferative function in osteoblasts. J Biol Chem 2005; 280: 20274-20285.

44. Yu S, Geng Q, Sun $\mathrm{F}, \mathrm{Yu}$ Y, Pan Q, Hong A. Osteogenic differentiation of $\mathrm{C} 2 \mathrm{C} 12$ myogenic progenitor cells requires the Fos-related antigen Fra-1-a novel target of Runx2. Biochem Biophys Res Commun 2013; 430: 173-178.

45. Sun $F$, Xie $Q$, Ma J, Yang $S$, Chen $Q$, Hong A. Nuclear factor $Y$ is required for basal activation and chromatin accessibility of fibroblast growth factor receptor 2 promoter in osteoblast-like cells. J Biol Chem 2008; 284: 3136-3147.

(c) (i) $(9)$ Cell Death and Disease is an open-access journal published by Nature Publishing Group. This work is licensed under a Creative Commons Attribution-NonCommercialNoDerivs 3.0 Unported License. To view a copy of this license, visit http://creativecommons.org/licenses/by-nc-nd/3.0/ 